\title{
Effects of the histamine $\mathrm{H}_{1}$ receptor antagonist and benztropine analog diphenylpyraline on dopamine uptake, locomotion and reward
}

\author{
Erik B. Oleson, Mark J. Ferris, Rodrigo A España, Jill Harp, and Sara R. Jones \\ Department of Physiology and Pharmacology, Wake Forest School of Medicine, Winston Salem, \\ North Carolina
}

\section{Abstract}

Diphenylpyraline hydrochloride (DPP) is an internationally available antihistamine that produces therapeutic antiallergic effects by binding to histamine $\mathrm{H}_{1}$ receptors. The complete neuropharmacological and behavioral profile of DPP, however, remains uncharacterized. Here we describe studies that suggest DPP may fit the profile of a potential agonist replacement medication for cocaine addiction. Aside from producing the desired histamine reducing effects, many antihistamines can also elicit psychomotor activation and reward, both of which are associated with increased dopamine concentrations in the nucleus accumbens (NAc). The primary aim of this study was to investigate the potential ability of DPP to inhibit the dopamine transporter, thereby leading to elevated dopamine concentrations in the NAc in a manner similar to cocaine and other psychostimulants. The psychomotor activating and rewarding effects of DPP were also investigated. For comparative purposes cocaine, a known dopamine transporter inhibitor, psychostimulant and drug of abuse, was used as a positive control. As predicted, both cocaine (15 $\mathrm{mg} / \mathrm{kg})$ and an equimolar dose of DPP $(14 \mathrm{mg} / \mathrm{kg})$ significantly inhibited dopamine uptake in the NAc in vivo and produced locomotor activation, although the time-course of pharmacological effects of the two drugs was different. In comparison to cocaine, DPP showed a prolonged effect on dopamine uptake and locomotion. Furthermore, cocaine, but not DPP, produced significant conditioned place preference, a measure of drug reward. The finding that DPP functions as a potent dopamine uptake inhibitor without producing significant rewarding effects suggests that DPP merits further study as a potential candidate as an agonist pharmacotherapy for cocaine addiction.

\section{Keywords}

agonist therapy; reward; psychostimulant; antihistamine; benztropine; dopamine

\section{Introduction}

Although generally assumed to be well understood and safe, many of the over 40 internationally available antihistamines have not been sufficiently characterized (Simons,

\footnotetext{
C 2012 Elsevier B.V. All rights reserved.

Corresponding Author: Sara R. Jones, Department of Physiology and Pharmacology, Wake Forest School of Medicine, Medical Center Blvd., Winston Salem, NC 27157 USA, srjones@ wakehealth.edu.

Publisher's Disclaimer: This is a PDF file of an unedited manuscript that has been accepted for publication. As a service to our customers we are providing this early version of the manuscript. The manuscript will undergo copyediting, typesetting, and review of the resulting proof before it is published in its final citable form. Please note that during the production process errors may be discovered which could affect the content, and all legal disclaimers that apply to the journal pertain.
} 
2004). The descriptors first- and second-generation are commonly used to divide antihistamines into two broadly defined pharmacological classes (Kay, 2000; Slater et al., 1999). Aside from producing the desired histamine reducing effects, first-generation antihistamines are known to produce an array of non-specific drug effects due to their ability to readily pass the blood brain barrier and interact with various neurotransmitter systems (Halpert et al., 2002; Slater et al., 1999). By contrast, second-generation antihistamines are more selective for histamine $\mathrm{H}_{1}$ receptors and produce peripheral antiallergic effects while exhibiting limited central antihistaminergic action (Slater et al., 1999).

Despite their well-documented ability to produce sedation (Nicholson et al., 1991; Quach et al., 1979), first-generation antihistamines can also paradoxically produce behavioral effects commonly associated with psychostimulants, including behavioral activation and reward (Halpert et al., 2002). For example, first-generation antihistamines have been shown to increase locomotor activity (Lapa et al., 2005b; Tanda et al., 2008), produce conditioned place preference (Halpert et al., 2002; Suzuki et al., 1999; Zimmermann et al., 1999) and facilitate rewarding effects of intra-cranial self-stimulation (Unterwald et al., 1984; Wauquier and Niemegeers, 1981; Zimmermann et al., 1999). First-generation antihistamines are also readily self-administered by animals (Banks et al., 2009; Wang and Woolverton, 2009).

Nucleus accumbens (NAc) dopamine levels are increased by psychostimulants and involved in motivational responses to reward-associated stimuli (Berridge and Robinson, 2003; Di Chiara and Imperato, 1988). It is possible therefore that the psychomotor activating and rewarding effects produced by first-generation antihistamines co-occur with increases in NAc dopamine. Indeed, first-generation antihistamines have been shown to increase NAc dopamine measured by in vivo microdialysis (Dringenberg et al., 1998; Tanda et al., 2008).

Diphenylpyraline hydrochloride (DPP), chemically known as 4-Diphenylmethoxy-1methylpiperidine hydrochloride, is an internationally available first-generation antihistamine (Hasegawa et al., 2006; Puhakka et al., 1977; Wishart et al., 2008) that was historically used as a pharmacotherapy for Parkinson's disease (Farnebo et al., 1970; Ohno et al., 2001), like other antihistamines (e.g., diphenhydramine) (Coyle and Snyder, 1969) that are now known to increase dopamine concentrations and produce rewarding effects (Tanda et al., 2008). The chemical structure of DPP is similar to a family of benztropine analogs known to bind to the dopamine transporter (Lapa et al., 2005a; Newman and Agoston, 1998), thereby increasing dopamine concentrations by inhibiting uptake.

Neither the rewarding effects of DPP nor the effects of DPP on dopamine uptake inhibition in vivo have been documented. Cocaine is a prototypical DAT blocker with strong activating and rewarding effects (Morency and Beninger, 1986; Nomikos and Spyraki, 1988). Therefore, cocaine was a logical choice for a positive control. In this study DPP, and an equimolar dose of cocaine, were compared in the following experiments: (1) dopamine uptake inhibiting effects were measured in vivo using fast-scan cyclic voltammetry (2) psychomotor activating effects were measured by assessing horizontal activity in the open field (3) rewarding effects were measured using conditioned place preference.

\section{Materials and methods}

\subsection{Animals}

C57BL/6J mice (Jackson Laboratories, Bar Harbor, Maine) were housed in groups of three or four in standard laboratory cages with food and water available ad libitum on a 12-h lightdark cycle (lights on at 7am). Different groups of animals were used for each study. All experiments were performed in male mice (3-4 months old) during the light cycle. All 
protocols were in accordance with the National Institutes of Health Animal Care Guidelines and were approved by the Wake Forest University Institutional Animal Care and Use Committee.

\subsection{Fast-scan cyclic voltammetry}

All fast-scan cyclic voltammetry experiments described in the present study were performed on anesthetized mice. Animals were anesthetized with urethane $(1 \mathrm{~g} / \mathrm{kg}$ i.p.) and placed in a stereotaxic frame adapted for mice. It should be noted that previous reports have demonstrated that urethane anesthesia does not alter dopamine uptake dynamics (Garris et al., 2003; Sabeti et al., 2003). The surgery for implantation of stimulating, working and reference electrodes was conducted as previously described for mice (Oleson et al., 2009). Briefly, a carbon fiber working electrode was lowered into the right NAc (AP: +1.0, ML: +1.3 , DV: $-4.5 \mathrm{~mm}$ from bregma) and a bipolar stimulating electrode was placed ipsilaterally in the ventral tegmental area/substantia nigra pars compacta region of the midbrain (AP: -3 , ML: +1.1, DV: $-4.7 \mathrm{~mm}$ from bregma). A Ag/AgCl reference electrode was implanted into the contralateral cortex. Dopamine was evoked by electrical stimulation of the midbrain and monitored in the NAc. Electrical stimulation (60 rectangular pulses, 60 $\mathrm{Hz}, 300 \mu \mathrm{A}, 2 \mathrm{~ms} / \mathrm{phase}$, biphasic) occurred every 5-10 min for $60 \mathrm{~min}$. Voltammetric recordings were made at the carbon fiber electrode every $100 \mathrm{~ms}$ by applying a triangle waveform $(-0.4$ to $+1.2 \mathrm{~V}, 300 \mathrm{~V} / \mathrm{s})$. Following the establishment of a stable baseline dopamine signal (at least three consecutive stable stimulations of dopamine) DPP ( $\mathrm{n}=5 ; 14$ $\mathrm{mg} / \mathrm{kg})$ or an equimolar concentration of cocaine $(\mathrm{n}=5 ; 15 \mathrm{mg} / \mathrm{kg})$ was administered intraperitoneally (i.p.). Voltammetric data were digitized (National Instruments, Austin, Texas) and stored on a computer. Carbon fiber working electrodes were calibrated in vitro with a known concentration of dopamine $(3 \mu \mathrm{M})$ following the completion of each experiment, and the magnitude of current at the peak oxidation potential was used to quantify the experimental dopamine signals obtained in vivo. Changes in stimulated dopamine release and uptake were modeled using a Michaelis-Menten based set of equations (Wu et al., 2001) to determine the kinetics of dopamine uptake. The dependent measure reported in the current study, apparent $K_{\mathrm{m}}$, represents the inverse of the apparent affinity of dopamine for the dopamine transporter in the presence or absence of drug (Wu et al., 2001).

\subsection{Locomotor testing}

Horizontal locomotor activity was assessed using open field activity monitors equipped with photosensors spaced $2.5 \mathrm{~cm}$ apart along 2 perpendicular walls $(43.2 \times 43.2 \times 30.5 \mathrm{~cm}$; MED Associates). One count of horizontal activity was registered each time a mouse interrupted a photosensor beam. Mice were habituated to the locomotor chambers for 1 hour before DPP $(\mathrm{n}=5 ; 14 \mathrm{mg} / \mathrm{kg}$ i.p.), cocaine $(\mathrm{n}=5 ; 15 \mathrm{mg} / \mathrm{kg}$ i.p.) or saline $(\mathrm{n}=7)$ was administered. Horizontal activity counts were binned into 1 min samples for 60 min after drug administration.

\subsection{Conditioned place preference}

The conditioned place preference apparatus consisted of two chambers $(13 \mathrm{~cm} \times 13 \mathrm{~cm} \times$ $20.3 \mathrm{~cm}$, Med Associated, St. Albans, VT) connected with a guillotine door, and tests were conducted using an unbiased design. The design for DPP $(14 \mathrm{mg} / \mathrm{kg})$ and cocaine $(15 \mathrm{mg} /$ $\mathrm{kg}$ ) was identical. During the preconditioning phase (day 1), mice were allowed free access for 25 min to both chambers. The conditioning phase (days 2-4) consisted of 2 sessions per day separated by 6 hours. In the morning session, mice received an i.p. injection of either drug ( $n=10$ for cocaine; $n=9$ for DPP) or saline in a volume of $0.1 \mathrm{~mL}$ and were immediately confined to one side of the apparatus for $25 \mathrm{~min}$. Mice were then returned to their home cage. Six hours following the first session, mice were given an injection of either drug or 
saline during the afternoon session, whichever they had not yet received, and confined to the opposite chamber for $25 \mathrm{~min}$. Side/drug pairing and drug/session pairing were counterbalanced. On day 5, mice were placed in the apparatus and allowed free access to both sides of the chamber. Side of entry was counterbalanced across drug-paired and unpaired sides during the testing process. Conditioned place preference was assessed by the amount of time spent in the drug paired side during the test phase minus the time spent in the drug paired side during the preconditioning phase over the 25 min period.

2.5 Drug

Cocaine hydrochloride (obtained from the National Institute on Drug Abuse, Rockville, MD, USA) and DPP (Sigma-Aldrich) were prepared in sterile $0.9 \%$ saline.

\subsection{Statistics}

All statistical analyses were performed using SYSTAT 11 Version 11.00.01. Apparent $K_{\mathrm{m}}$ and horizontal activity comparisons were performed using repeated measures analysis of variance (ANOVA) with Holm-Sidak post hoc analysis. Conditioned place preference comparisons were performed using one-sample t-tests. The criterion of significance was set at $P<0.05$.

\section{Results}

\subsection{DPP and cocaine inhibit dopamine uptake with different time courses}

To assess whether DPP inhibits dopamine uptake in vivo we used fast-scan cyclic voltammetry to measure drug-induced changes in apparent $K_{\mathrm{m}}$ in the NAc of anesthetized mice. Fig. 1 illustrates that DPP potently inhibits dopamine uptake in the mouse NAc in a manner similar to cocaine, albeit along a different time-course. A two-way repeated measures ANOVA revealed a significant time by drug-treatment interaction $\left(\mathrm{F}_{7,56}=13.412\right.$; $\mathrm{P}<0.01$ ). Maximal dopamine uptake inhibition was observed $40 \mathrm{~min}$ after DPP and $30 \mathrm{~min}$ after cocaine administration. Post hoc tests revealed that DPP exhibited a prolonged effect on dopamine uptake inhibition in comparison to cocaine. DPP treated mice showed a significantly higher apparent $K_{\mathrm{m}}$ after $40(\mathrm{t}=3.275 ; \mathrm{P}<0.01), 50(\mathrm{t}=4.473 ; \mathrm{P}<0.01)$ and 60 $(\mathrm{t}=4.699 ; \mathrm{P}<0.01) \mathrm{min}$ in comparison to cocaine treated mice.

\subsection{DPP and cocaine induce psychomotor activation with different time courses}

To assess the psychomotor activating effects of DPP we compared the effects of a cocaine dose $(15 \mathrm{mg} / \mathrm{kg}$ ) commonly used to measure changes in locomotor activity (Kalivas and Duffy, 1993) to an equimolar dose of DPP (14 mg/kg). As illustrated in Fig. 2, DPP significantly increased horizontal activity in a manner similar to cocaine, but with a longer time course. A two-way repeated measures ANOVA revealed a significant time by drugtreatment interaction $\left(\mathrm{F}_{124,867}=4.405 ; \mathrm{P}<0.01\right)$. Post hoc tests revealed that in comparison to DPP, cocaine produced greater horizontal activity at $6-12,14,15$ and $17 \mathrm{~min}$. In accordance with the dopamine uptake inhibition data, post hoc tests further revealed that DPP exhibited a prolonged effect on locomotion in comparison to cocaine. In comparison to vehicle treatment, the effect of cocaine on horizontal activity was no longer significant after $27 \mathrm{~min}$ whereas the DPP-induced increases in horizontal activity persisted through $38 \mathrm{~min}$.

\subsection{Cocaine, but not DPP, produced rewarding effects}

To assess whether DPP produces rewarding effects we examined whether DPP (14 mg/kg) or cocaine $(15 \mathrm{mg} / \mathrm{kg})$ induced a conditioned place preference to a drug paired environment. As illustrated in Fig. 3, of the two drugs, only cocaine produced a conditioned place preference. One sample $t$-tests revealed that cocaine treated mice $(t=4.06 ; \mathrm{P}<0.01)$ but not 
DPP treated mice $(t=1.94 ;$ n.s. $)$ spent significantly more time in the drug-paired side of the conditioned place preference apparatus in comparison to preconditioning values.

\section{Discussion}

In the present study the neurochemical and behavioral effects of DPP, a first-generation histamine $\mathrm{H}_{1}$ receptor binding antihistamine (Hasegawa et al., 2006; Puhakka et al., 1977) and benztropine analog (Lapa et al., 2005a), were investigated in comparison to cocaine. As predicted, both DPP and cocaine significantly inhibited dopamine uptake in the NAc in vivo and produced psychomotor activation, although the time-course of pharmacological action between the two drugs was distinct. Specifically, DPP produced a prolonged effect on dopamine uptake and locomotor activity in comparison to cocaine while also showing a delayed peak effect. In addition to exhibiting distinct pharmacodynamics/pharmacokinetics, the two drugs differed in their ability to produce reward-associated effects. Cocaine, but not DPP, produced a significant conditioned place preference. The finding that DPP failed to produce rewarding effects despite functioning as a potent dopamine uptake inhibitor suggests that DPP merits further study as a potential candidate as an agonist pharmacotherapy for cocaine addiction.

These results provide in vivo verification, consistent with our previous in vitro report (Lapa et al., 2005b), that DPP inhibits dopamine uptake in the NAc. Although antihistamineinduced increases in NAc dopamine have previously been attributed to $\mathrm{H}_{1}$-histamine receptor mediated disinhibition of dopamine neural activity (Fischer et al 2010; Korotkovka et al 2002), this is unlikely to be the primary pharmacological mechanism because the dopamine-increasing potency of antihistamines does not correlate with $\mathrm{H}_{1}$-histamine receptor affinity (Tanda 1998). Instead, our data support the idea that antihistamine-induced increases in NAc dopamine are primarily due to dopamine uptake inhibition (Coyle and Snyder, 1969; Matsunaga et al., 1998; Tanda et al., 2008). The data from the current study further demonstrate that DPP produces locomotor hyperactivity, which confirms that firstgeneration antihistamines can produce stimulant-like effects (Lapa et al., 2005b; Tanda et al., 2008) despite the sedative effects typically observed with antagonism of central histamine $\mathrm{H}_{1}$ receptors (Nicholson et al., 1991; Quach et al., 1979; Hindmarch and Shamsi 1999).

Although both DPP and cocaine potently inhibited dopamine uptake in vivo and induced locomotor activation, the two drugs showed different pharmacodynamic/pharmacokinetic profiles. Although both DPP and cocaine inhibited dopamine uptake at the first time-point assessed (i.e., $5 \mathrm{~min}$ ), DPP exhibited delayed peak effects ( $40 \mathrm{~min}$ vs. $30 \mathrm{~min}$ ) and offset kinetics in comparison to cocaine. These observations are consistent with a previous report (Yorgason et al., 2011) in which we demonstrated that several tropane analogs (e.g., PTT, GBR12909) known to produce unique behavioral profiles from cocaine (Nader et al 1997, Katz et al 1999), display similar onset kinetics but different peak and offset kinetics. Moreover, in comparison to cocaine, DPP treated mice showed an attenuated maximal psychomotor response with a delayed offset. It is likely that DPP produced an attenuated maximal psychomotor in comparison to cocaine despite comparably inhibiting dopamine uptake due to physiological antagonism. That is, like cocaine, DPP increases psychomotor activation by inhibiting dopamine uptake, but the effects of DPP on locomotion might be diminished by the additional sedative effects produced by antagonism of central $\mathrm{H}_{1}$ histamine receptors (Nicholson et al., 1991; Quach et al., 1979; Hindmarch and Shamsi 1999).

Importantly, DPP failed to produce significant rewarding effects. Various benztropine analogs have been shown to inhibit dopamine uptake without posing a high abuse liability 
(Hiranita et al., 2009; Rothman, 1990), and in some cases they even reduce the reinforcing effectiveness of cocaine (Hiranita et al 2009; Nader et al 1997). The results from the present study suggest that benztropines showing a delayed peak effect and slow offset kinetics may be less likely to produce rewarding effects.

Taken together, these results suggest DPP may exhibit a promising profile as a potential agonist treatment for cocaine addiction. The finding that DPP binds to the dopamine transporter but dissociates slowly suggests that DPP could potentially compete with cocaine at the dopamine transporter, and thereby reduce the effectiveness of cocaine (Howell and Wilcox, 2001; Rothman et al., 2008; Tanda et al., 2009). In addition, it has been suggested that researchers should focus on medications that have parallel, yet attenuated behavioral actions in comparison to cocaine (Grabowski et al., 2004; Platt et al., 2002; Shearer, 2008). DPP fits this neuropharmacological and behavioral profile. Specifically, DPP: 1) interacts with the dopamine transporter in a manner that should compete with cocaine 2) exhibits a distinct pharmacodynamic/pharmacokinetic profile from cocaine 3 ) produces attenuated but prolonged effects on psychomotor activation in comparison to cocaine 4) fails to produce robust rewarding effects in comparison to cocaine. It should be noted, however, that most clinically effective agonist pharmacotherapies for cocaine addiction produce rewarding and reinforcing effects in their own right, which likely contributes to patient adherence (Mooney et al., 2009; Herin et al., 2011). Whether other doses of DPP might produce modest rewarding or reinforcing effects should be determined. Future drug-binding and selfadministration studies using extensive dose-effect functions, in addition to assessing the effects of chronic dosing, will provide necessary information regarding whether DPP should advance as a candidate pharmacotherapy for cocaine addiction.

\section{Acknowledgments}

This work was supported by grants R01DA021325 and DA030161 (SRJ), MD00232 (JJH and SRJ), K01DA025279 (RAE) and T32DA007246 (MJF) from the National Institute of Health.

\section{References}

Banks ML, Andersen ML, Murnane KS, Meyer RC, Howell LL. Behavioral and neurochemical effects of cocaine and diphenhydramine combinations in rhesus monkeys. Psychopharmacology (Berl). 2009; 205:467-474. [PubMed: 19430765]

Berridge KC, Robinson TE. Parsing reward. TRENDS in Neurosciences. 2003; 26:507-513. [PubMed: 12948663]

Coyle JT, Snyder SH. Antiparkinsonian drugs: inhibition of dopamine uptake in the corpus striatum as a possible mechanism of action. Science. 1969; 166:899-901. [PubMed: 5345207]

Di Chiara G, Imperato A. Drugs abused by humans preferentially increase synaptic dopamine concentrations in the mesolimbic system of freely moving rats. Proc Natl Acad Sci USA. 1988; 85:5274-5278. [PubMed: 2899326]

Dringenberg HC, de Souza-Silva MA, Schwarting RK, Huston JP. Increased levels of extracellular dopamine in neostriatum and nucleus accumbens after histamine H1 receptor blockade. Naunyn Schmiedebergs Arch Pharmacol. 1998; 358:423-429. [PubMed: 9826064]

Farnebo LO, Fuxe K, Hamberger B, Ljungdahl H. Effect of some antiparkinsonian drugs on catecholamine neurons. J Pharm Pharmacol. 1970; 22:733-737. [PubMed: 4394777]

Garris PA, Budygin EA, Phillips PE, Venton BJ, Robinson DL, Bergstrom BP, Rebec GV, Wightman $\mathrm{RM}$. A role for presynaptic mechanisms in the actions of nomifensine and haloperidol. Neuroscience. 2003; 118:819-829. [PubMed: 12710989]

Grabowski J, Shearer J, Merrill J, Negus SS. Agonist-like, replacement pharmacotherapy for stimulant abuse and dependence. Addict Behav. 2004; 29:1439-1464. [PubMed: 15345275]

Halpert AG, Olmstead MC, Beninger RJ. Mechanisms and abuse liability of the anti-histamine dimenhydrinate. Neurosci Biobehav Rev. 2002; 26:61-67. [PubMed: 11835984] 
Hasegawa C, Kumazawa T, Lee XP, Fujishiro M, Kuriki A, Marumo A, Seno H, Sato K. Simultaneous determination of ten antihistamine drugs in human plasma using pipette tip solid-phase extraction and gas chromatography/mass spectrometry. Rapid Commun Mass Spectrom. 2006; 20:537-543. [PubMed: 16419026]

Herin DV, Rush CV, Grabowski J. Agonist-like pharmacotherapy for stimulant dependence: preclinical, human laboratory, and clinical studies. Ann NY Acad Sci. 2010; 1187:76-100. [PubMed: 20201847]

Hiranita T, Soto PL, Newman AH, Katz JL. Assessment of reinforcing effects of benztropine analogs and their effects on cocaine self-administration in rats: comparisons with monoamine uptake inhibitors. Journal of Pharmacology and Experimental Therapeutics. 2009; 329:677. [PubMed: 19228996]

Kalivas PW, Duffy P. Time course of extracellular dopamine and behavioral sensitization to cocaine. I. Dopamine axon terminals. J Neurosci. 1993; 13:266-275. [PubMed: 8423473]

Kay GG. The effects of antihistamines on cognition and performance. J Allergy Clin Immunol. 2000; 105:S622-627. [PubMed: 10856168]

Lapa GB, Byrd GD, Lapa AA, Budygin EA, Childers SR, Jones SR, Harp JJ. The synthesis and biological evaluation of dopamine transporter inhibiting activity of substituted diphenylmethoxypiperidines. Bioorg Med Chem Lett. 2005a; 15:4915-4918. [PubMed: 16165350]

Lapa GB, Mathews TA, Harp J, Budygin EA, Jones SR. Diphenylpyraline, a histamine H1 receptor antagonist, has psychostimulant properties. Eur J Pharmacol. 2005b; 506:237-240. [PubMed: 15627433]

Matsunaga K, Sato T, Shuto H, Tsuruta Y, Suemaru K, Gomita Y, Oishi R. Inhibition of neuronal dopamine uptake by some antiallergic drugs. Eur J Pharmacol. 1998; 350:165-169. [PubMed: 9696404]

Mooney ME, Herin DV, Schmitz JM, Moukaddam N, Green CE, Grabowski J. Effects of oral methamphetamine on cocaine use: a randomized, double-blind, placebo-controlled trial. Drug Alcohol Depend. 2009; 101:34-41. [PubMed: 19058926]

Morency MA, Beninger RJ. Dopaminergic substrates of cocaine-induced place conditioning. Brain Res. 1986; 399:33-41. [PubMed: 3026573]

Newman AH, Agoston GE. Novel benztropine [3a-(diphenylmethoxy)tropane] analogs as probes for the dopamine transporter. Curr Med Chem. 1998; 5:305-319. [PubMed: 9668197]

Nicholson AN, Pascoe PA, Turner C, Ganellin CR, Greengrass PM, Casy AF, Mercer AD. Sedation and histamine H1-receptor antagonism: studies in man with the enantiomers of chlorpheniramine and dimethindene. Br J Pharmacol. 1991; 104:270-276. [PubMed: 1686208]

Nomikos GG, Spyraki C. Cocaine-induced place conditioning: importance of route of administration and other procedural variables. Psychopharmacology (Berl). 1988; 94:119-125. [PubMed: 3126520]

Ohno T, Kobayashi S, Hayashi M, Sakurai M, Kanazawa I. Diphenylpyraline-responsive parkinsonism in cerebrotendinous xanthomatosis: long-term follow up of three patients. J Neurol Sci. 2001; 182:95-97. [PubMed: 11137513]

Oleson EB, Salek J, Bonin KD, Jones SR, Budygin EA. Real-time voltammetric detection of cocaineinduced dopamine changes in the striatum of freely moving mice. Neurosci Lett. 2009; 467:144146. [PubMed: 19822192]

Platt DM, Rowlett JK, Spealman RD. Behavioral effects of cocaine and dopaminergic strategies for preclinical medication development. Psychopharmacology (Berl). 2002; 163:265-282. [PubMed: 12373428]

Puhakka H, Rantanen T, Virolainen E. Diphenylpyraline (Lergobine) in the treatment of patients suffering from allergic and vasomotor rhinitis. J Int Med Res. 1977; 5:37-41. [PubMed: 14039]

Quach TT, Duchemin AM, Rose C, Schwartz JC. In vivo occupation of cerebral histamine H1receptors evaluated with $3 \mathrm{H}$-mepyramine may predict sedative properties of psychotropic drugs. Eur J Pharmacol. 1979; 60:391-392. [PubMed: 43262]

Rothman RB. High affinity dopamine reuptake inhibitors as potential cocaine antagonists: A strategy for drug development. Life sciences. 1990; 46:PL17-PL21. [PubMed: 2111866] 
Sabeti J, Gerhardt GA, Zahniser NR. Chloral hydrate and ethanol, but not urethane, alter the clearance of exogenous dopamine recorded by chronoamperometry in striatum of unrestrained rats. Neurosci Lett. 2003; 343:9-12. [PubMed: 12749985]

Shearer J. The principles of agonist pharmacotherapy for psychostimulant dependence. Drug Alcohol Rev. 2008; 27:301-308. [PubMed: 18368612]

Simons FE. Advances in H1-antihistamines. N Engl J Med. 2004; 351:2203-2217. [PubMed: 15548781]

Slater JW, Zechnich AD, Haxby DG. Second-generation antihistamines: a comparative review. Drugs. 1999; 57:31-47. [PubMed: 9951950]

Suzuki T, Mori T, Tsuji M, Nomura M, Misawa M, Onodera K. Evaluation of the histamine H1antagonist-induced place preference in rats. Jpn J Pharmacol. 1999; 81:332-338. [PubMed: 10669037]

Tanda G, Kopajtic TA, Katz JL. Cocaine-like neurochemical effects of antihistaminic medications. J Neurochem. 2008; 106:147-157. [PubMed: 18363822]

Unterwald EM, Kucharski LT, Williams JE, Kornetsky C. Tripelennamine: enhancement of brainstimulation reward. Life Sci. 1984; 34:149-153. [PubMed: 6607395]

Wang Z, Woolverton WL. Super-additive interaction of the reinforcing effects of cocaine and H1antihistamines in rhesus monkeys. Pharmacol Biochem Behav. 2009; 91:590-595. [PubMed: 18930758]

Wauquier A, Niemegeers CJ. Effects of chlorpheniramine, pyrilamine and astemizole on intracranial self-stimulation in rats. Eur J Pharmacol. 1981; 72:245-248. [PubMed: 6113975]

Wishart DS, Knox C, Guo AC, Cheng D, Shrivastava S, Tzur D, Gautam B, Hassanali M. DrugBank: a knowledgebase for drugs, drug actions and drug targets. Nucleic Acids Res. 2008; 36:D901-906. [PubMed: 18048412]

Wu Q, Reith ME, Wightman RM, Kawagoe KT, Garris PA. Determination of release and uptake parameters from electrically evoked dopamine dynamics measured by real-time voltammetry. J Neurosci Methods. 2001; 112:119-133. [PubMed: 11716947]

Yorgason JT, Jones SR, Espana RA. Low and high affinity dopamine transporter inhibitors block dopamine uptake within $5 \mathrm{sec}$ of intravenous injection. Neuroscience. 2011; 182:125-132. [PubMed: 21402130]

Zimmermann P, Privou C, Huston JP. Differential sensitivity of the caudal and rostral nucleus accumbens to the rewarding effects of a H1-histaminergic receptor blocker as measured with place-preference and self-stimulation behavior. Neuroscience. 1999; 94:93-103. [PubMed: 10613500] 


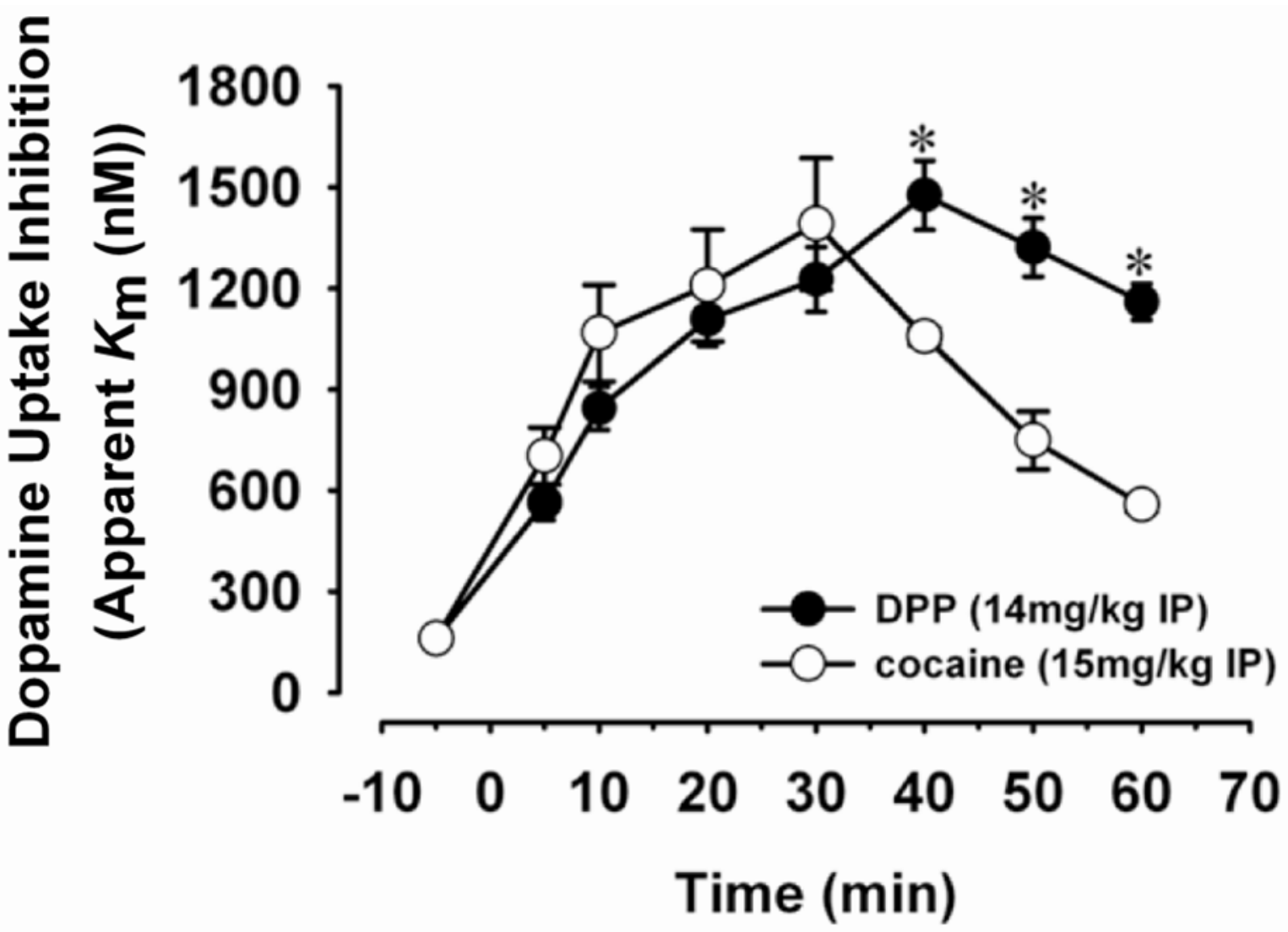

Fig. 1.

Effects of DPP (black circles) and cocaine (white circles) on dopamine uptake inhibition (Apparent $K_{\mathrm{m}}$ ) over $60 \mathrm{~min}$. Data are expressed as mean $( \pm$ S.E.M.) and asterisks indicate a significant difference in dopamine uptake between DPP and cocaine treated mice. 


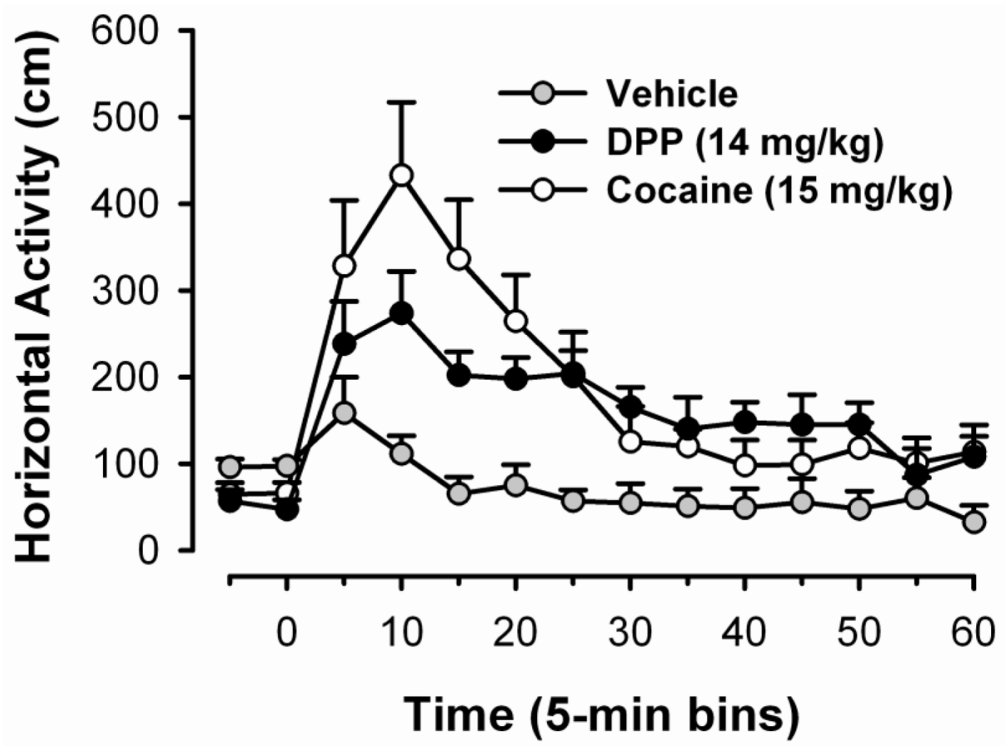

Fig. 2.

Effects of DPP (black circles), cocaine (white circles) and vehicle (gray circles) on psychomotor activation (horizontal activity counts). Data are expressed as mean ( \pm S.E.M.). 


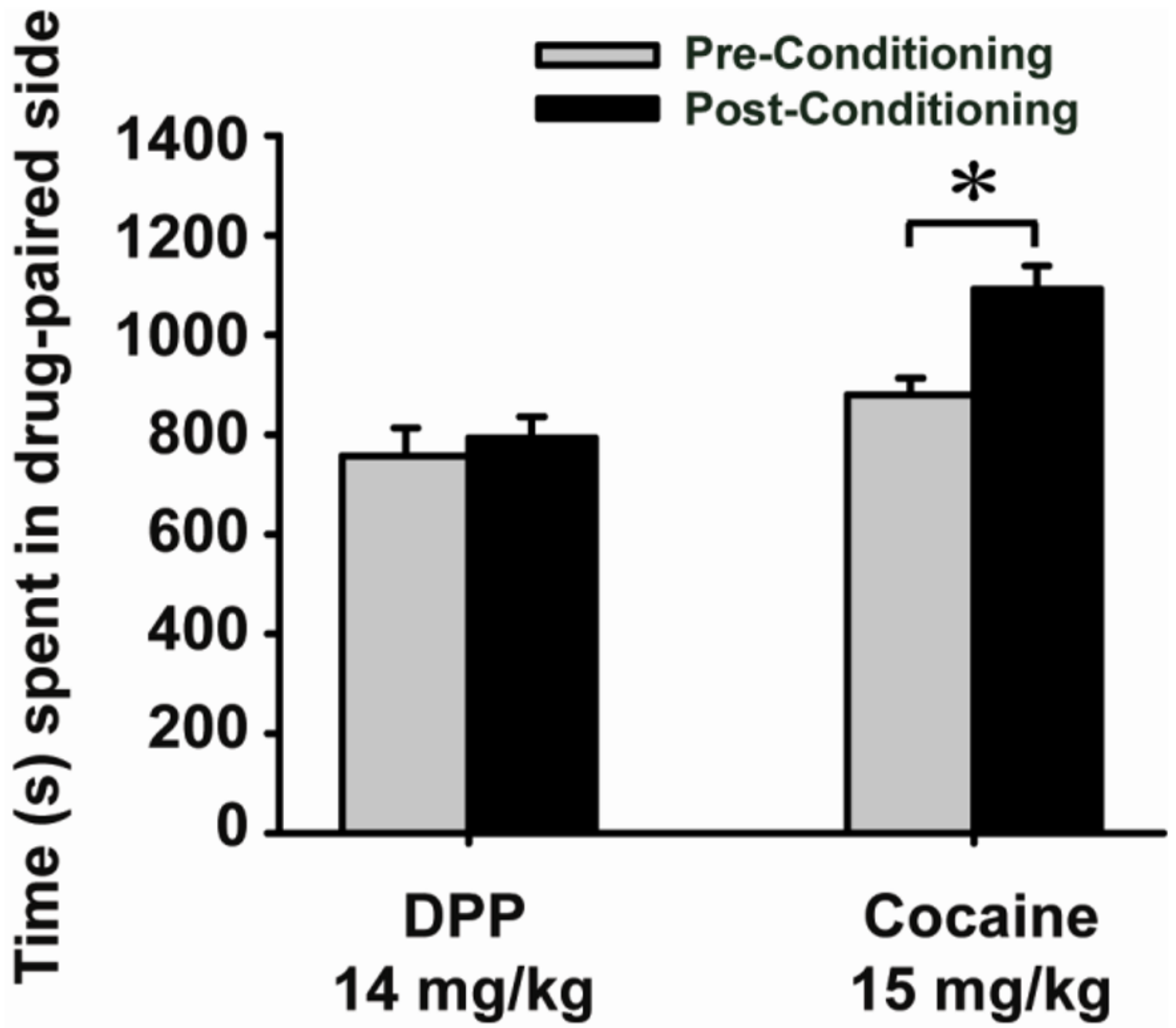

Fig. 3.

Effects of DPP and cocaine on conditioned place preference before (gray bars) and after (black bars) conditioning. Data are expressed as mean $( \pm$ S.E.M.) and asterisks indicate a significant difference in place preference. 